Check for updates

Cite this: RSC Adv., 2018, 8, 21850

\title{
Creating magnetic ionic liquid-molecularly imprinted polymers for selective extraction of lysozyme $\uparrow$
}

\author{
Wei Xu, ${ }^{a}$ Qingzhou Dai, ${ }^{a}$ Yuzhi Wang, (D) *a Xiaojian Hu, ${ }^{\text {b }}$ Panli $\mathrm{Xu}{ }^{\mathrm{a}}$ Rui Ni ${ }^{\mathrm{a}}$ \\ and Jiaojiao Meng ${ }^{a}$
}

A novel magnetic $\left(\mathrm{Fe}_{3} \mathrm{O}_{4}\right)$ surface molecularly imprinted polymer (MIP) based on ionic liquid (IL) ( $\mathrm{Fe}_{3} \mathrm{O}_{4}$ QVTEOQIL-MIPs) was prepared for the selective extraction of lysozyme (Lys). As the functional monomer of the MIPs, an imidazolium-based IL with vinyl groups was prepared. It can provide multiple interactions with template molecules. The amount of IL was optimized $(200 \mathrm{mg})$. Fourier transform infrared spectrometry (FT-IR), transmission electron microscopy (TEM), dynamic light scattering (DLS), thermogravimetric analysis (TGA) and a vibrating sample magnetometer (VSM) were used to characterize the MIP. The results indicate the successful formation of an imprinting polymer layer. The concentration of Lys in the supernatant was determined by UV-vis spectrophotometry at a wavelength of $280 \mathrm{~nm}$. The maximum adsorption capability of the MIP is $213.7 \mathrm{mg} \mathrm{g}^{-1}$ and the imprinting factor (IF) is 2.02. It took $2.5 \mathrm{~h}$ for the MIP to attain adsorption equilibrium. The structure of the protein was evaluated using circular dichroism (CD) spectra and UV-visible spectra. The adsorption performance was further investigated in detail by selective adsorption experiments, competitive rebinding tests, and reusability and stability experiments. Furthermore, it was utilized to separate the template protein from a mixture of proteins and

Received 4th May 2018

Accepted 8th June 2018

DOI: $10.1039 / \mathrm{c} 8 \mathrm{ra03818j}$

rsc.li/rsc-advances real samples successfully because of the high adsorption capacity for Lys.

\section{Introduction}

Molecular imprinting technology (MIT) offers a way to design and prepare functional materials that have unique features of structural predictability and selective extraction. The functional materials are called molecularly imprinted polymers (MIPs). MIPs have tailor-made imprinted cavities, which are complementary to the template molecules in size, shape and functional groups and can interact with template molecules. ${ }^{1}$ Conceptually, templates, cross-linkers, functional monomers, a polymerization initiator and a solvent (porogen) are used to prepare typical MIPs. ${ }^{2}$ After removal of the template molecules, the artificial affinity binding cavities remain. Different methods have been employed to synthesize MIPs, such as surface imprinting, epitope imprinting and metal-chelating imprinting. ${ }^{3}$ Surface imprinting has some fascinating features. For example, template molecules can lightly access to the imprinted cavities in the surface of MIPs. Furthermore, it is

${ }^{a}$ State Key Laboratory of Chemo/Biosensing and Chemometrics, College of Chemistry and Chemical Engineering, Hunan University, Changsha, 410082, P. R. China. E-mail: wyzss@hnu.edu.cn; Fax: +86-731-88821848; Tel: +86-731-88821903

${ }^{b}$ Department of Chemistry, School of Basic Medicine, Changsha Medical University, Changsha, 410219, P. R. China

† Electronic supplementary information (ESI) available. See DOI: $10.1039 / \mathrm{c} 8 \mathrm{ra03818j}$ easy to elute the template molecules. Owing to unique features of structure predictability and selective extraction, MIPs have achieved lots of successful applications involving solid-phase extraction, drug delivery applications, biosensors and so on. ${ }^{4-6}$

Magnetic molecularly imprinted polymers have attracted increasing attention in recent years. ${ }^{7-10} \mathrm{Fe}_{3} \mathrm{O}_{4}$ magnetic nanoparticles have large surface areas, good biocompatibility and high chemical stability. After coating with functional layers, other good properties can be introduced into magnetic materials, which makes it become an important role in molecular imprinting technology. More importantly, compared with the traditional operation steps of solid phase separation, the magnetic MIPs particles can be fast separated by an external magnetic field. And complicated centrifugation steps can be avoided. Last but not least, $\mathrm{Fe}_{3} \mathrm{O}_{4}$ nanoparticles can provide the support material for the MIPs, which is important to synthesis core-shell structure. Magnetic materials was used widely in chemical, medical science and biological. ${ }^{8}$ Obviously, the polymer particles with magnetism is a must.

Proteins have complex conformation, flexible structure and large size. The activities of enzymes are affected easily, such as immobilization process, operation temperature, $\mathrm{pH}$ and humidity. ${ }^{11}$ Unlike some small molecule compounds, the synthesis process of imprinting enzymes needs to be carried out under mild conditions. Furthermore, another challenge faced by bio-macromolecules for imprinting applications is diffusion 
limitation. Removing and rebinding template are difficult. It is pretty important to remove template molecules completely to obtain the effective imprinted sites. ${ }^{12}$ So that the preparation of molecularly imprinted polymer for the bio-macromolecules is difficult. ${ }^{13}$ Lysozyme (Lys) is considered as an important index in the diagnosis of various diseases involving bronchopulmonary dysplasia in newborns, kidney problems, conjunctivitis and leukemia. ${ }^{\mathbf{1 4}, 15}$ Meanwhile, Lys has specific hydrolytic activity against bacterial cell walls and it is nontoxic to humans, which has been widely used as an antimicrobial agent in the production of wine, cheese and so on. ${ }^{15}$ So it is necessary to enrich Lys with high selectivity.

Ionic liquids (ILs) are regarded as "green solvents". ${ }^{16}$ ILs have interesting physicochemical properties such as high chemical stability, negligible vapour pressure, non-flammability, high ionic conductivity. In addition, it has the capability to attract dissolved molecules by a variety of interactions. ${ }^{17,18}$ The multiple interactions involve the electrostatic interaction, hydrogen bonding, $\pi-\pi$ stacking and ion exchange. In order to form task-specific ionic liquids (TSILs) interacting with analytes or substrates in specific ways, functional groups can be introduced to either component. ${ }^{19}$ In MIPs, the selection of functional monomers is important. It can form a pre-polymerization complex with the template and strongly interact with the templates by providing functional groups. ${ }^{2}$ The number of functional monomers is limited, but more and more ILs have achieved successful application as functional monomers in MIPs. ${ }^{20-22}$ A kind of task-specific ionic liquid can be designed to meet the needs of being a functional monomer. Imidazoliumbased IL with vinyl groups was prepared as the functional monomer in this work, which can provide multiple interactions with template molecules.

In this manuscript, we designed and fabricated magnetic surface imprinted polymers using ionic liquid as the functional monomer for selective extraction of lysozyme (as indicated in Scheme 1). Magnetic $\mathrm{Fe}_{3} \mathrm{O}_{4}$ nanoparticles modified with vinyltriethoxysilane (VTEO) were adopted as the support material. The prepared MIPs $\left(\mathrm{Fe}_{3} \mathrm{O}_{4} @\right.$ QVTEO@IL-MIPs) were characterized by transmission electron microscope (TEM), dynamic light scattering (DLS), thermogravimetric analysis (TGA), X-ray diffraction (XRD), vibrating sample magnetometer (VSM) and fourier transform infrared spectrometry (FT-IR). The secondary structure of the protein was evaluated by the circular dichroism (CD) spectra. $^{23}$ Furthermore, UV-visible spectra was used to investigate the structure of the protein. Meanwhile, the adsorption performance were further investigated in detail by selective adsorption experiments, competitive rebinding tests, reusability and stability experiments and real sample adsorption experiments.

\section{Experimental section}

\subsection{Apparatus}

A UV-2450 UV-vis spectrophotometer (Shimadzu, Japan) was used for determination of proteins. A FT-IR spectrometer (PerkinElmer, USA) was used to recorded infrared spectra. The morphologies nanomaterials were examined over a HT-7700 transmission electron microscope (TEM, Hitachi, Japan). Thermo-gravimetric analysis (TAG) was investigated by a STA 409 thermal gravimetric analyzer (Netzsch, Germany) under nitrogen atmosphere. X-ray diffraction pattern (XRD) was collected on a D/Max 2500 X-ray diffraction (Rigaku, Japan). An EV11 Vibrating Sample Magnetometer (MicroSense, USA) was employed to research the magnetism of samples. A Mos-500 circular dichroism (CD) spectrometer (Biologic, France) was applied to determine the secondary structure of Lys. Zetasizer Nano-ZS90 (Malvern Instruments, U.K.) was employed to

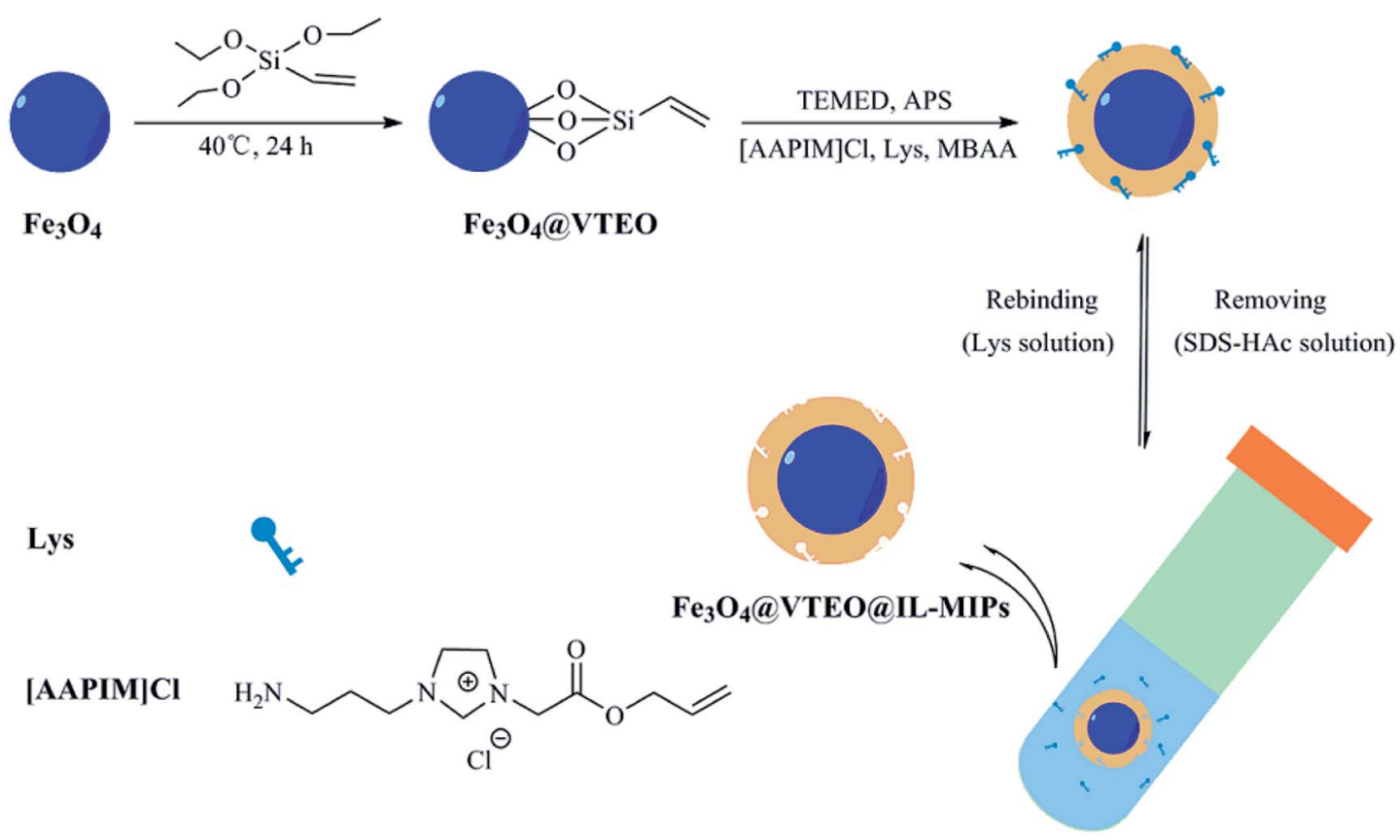

Scheme 1 Schematic illustration of the procedure for surface imprinting of Lys. 
research dynamic light scattering (DLS) study. A JY300C Gel electrophoresis (Beijing Junyi Eastern Electrophoresis Equipment Co., Ltd., China) was used to separate proteins.

\subsection{Reagents and materials}

Ammonium hydroxide solution $(27 \%, \mathrm{~W} / \mathrm{V}), \mathrm{FeCl}_{3} \cdot 6 \mathrm{H}_{2} \mathrm{O}$, $\mathrm{FeSO}_{4} \cdot 7 \mathrm{H}_{2} \mathrm{O}, \quad N, N, N^{\prime}, N^{\prime}$-tetramethylenediamine (TEMED), absolute ethanol, acetic acid (HAc) were bought from Sinopharm Chemical Reagent Co., Ltd. (Shanghai, China). Ovalbumin (OVA), bovine serum albumin (BSA), bovine hemoglobin (BHb), cytochrome C (Cyt C) and lysozyme (Lys) were purchased from Shanghai yuanye Bio-Technology Co., Ltd. (Shanghai, China). Allyl chloroacetate and $N, N$-methylenebisacrylamide (MBAA) were purchased from Aladdin chemistry Co., Ltd. (Shanghai, China). Vinyltriethoxysilane (VTEO) was obtained from Adamas Reagent Co., Ltd. (Shanghai, China). $\mathrm{N}$-(3aminopropyl)-imidazole was gained from TCI Development Co., Ltd. (Shanghai, China). Hydrazine hydrate and ammonium persulfate (APS) were bought from the Institute of Fucheng Chemicals (Tianjin, China). Sodium dodecyl sulfate (SDS) was supplied by Xilong chemistry Co., Ltd. (Shantou, China). All reagents were of analytical grade. All solutions were prepared using deionized water $\left(18.25 \mathrm{M} \Omega \mathrm{cm}, 25^{\circ} \mathrm{C}\right)$. Phosphate buffer solutions $\left(20 \mathrm{mmol} \mathrm{L}^{-1}, \mathrm{pH}=7.1\right)$ were used in this work for most experiments.

\subsection{Preparation of magnetic ionic liquid-molecularly imprinted polymers $\left(\mathrm{Fe}_{3} \mathrm{O}_{4} @\right.$ @VTEO@IL-MIPs)}

2.3.1. Synthesis of 1 -( $\alpha$-allylacetate)-3- $N$-(3-aminopropyl)imidazolium chloride (IL). 1-( $\alpha$-allylacetate)-3- $N$-(3aminopropyl)-imidazolium chloride ([AAPIM]Cl) was synthesized on the basis of Fig. 1. Briefly, $N$-(3-aminopropyl)-imidazole ( $6 \mathrm{~mL}, 50.1 \mathrm{mmol}$ ) was dissolved in ethyl acetate. Then, allyl chloroacetate $(5 \mathrm{~mL}, 43.6 \mathrm{mmol})$ was added dropwise to the stirred solution for reflux condensation. A light yellow sticky fluid was obtained after reaction for $12 \mathrm{~h}$ at $90{ }^{\circ} \mathrm{C}$. The crude fluid was washed with ethyl acetate several times to remove residual reactant, and then dried under vacuum for $24 \mathrm{~h}$.

2.3.2. Synthesis of vinyl functionalized magnetic microspheres $\left(\mathrm{Fe}_{3} \mathrm{O}_{4} @ V T E O\right)$. The magnetic $\mathrm{Fe}_{3} \mathrm{O}_{4}$ nanoparticles were synthesized as described in a previous work. ${ }^{24}$ The vinyl groups were introduced on the surface of $\mathrm{Fe}_{3} \mathrm{O}_{4}$ nanoparticles according to the method reported in literature with some modification. ${ }^{25}$ Compared with introducing vinyl groups by stirring, this method can synthesis more stable vinyl functionalized magnetic microspheres. Typically, $\mathrm{Fe}_{3} \mathrm{O}_{4}$ nanoparticles $(500 \mathrm{mg})$ were dispersed into the solution containing $100 \mathrm{~mL}$ of ethanol, $25 \mathrm{~mL}$ of deionized water, and $3.5 \mathrm{~mL}$ of ammonia via ultrasonication. After 20 min stirring, vinyltriethoxysilane (2.5 $\mathrm{mL}$ ) was added slowly to the solution. The reaction was continued under stirring for $24 \mathrm{~h}$ at $40{ }^{\circ} \mathrm{C}$. Subsequently, the vinyl functionalized microspheres were washed repeatedly with absolute ethanol and distilled water, respectively. Finally, the $\mathrm{Fe}_{3} \mathrm{O}_{4} @ V T E O$ microspheres were dried under freeze-drying conditions.

2.3.3. Synthesis of magnetic ionic liquid-molecularly imprinted polymers microspheres $\left(\mathrm{Fe}_{3} \mathrm{O}_{4} @ V T E O @ I L-M I P s\right)$. $\mathrm{Fe}_{3} \mathrm{O}_{4} @ V T E O @ I L-M I P s$ microspheres were prepared with free radical polymerization as described in the following. The activities of enzymes are affected easily, such as immobilization process, operation temperature, $\mathrm{pH}$ and humidity. So, the process of preparation MIPs for Lys must be in phosphate buffer solution. Firstly, $0.2 \mathrm{~g}$ of [AAPIM]Cl (monomer) was dissolved in $10 \mathrm{~mL}$ of phosphate buffer solution (pH 7.1). It didn't change the structures of Lys according to the UV-visible spectra and Gai et al. used phosphate buffer solution $\mathrm{pH} 7.0$ to prepare lysozyme surface-imprinted polymer. ${ }^{26}$ Secondly, $0.025 \mathrm{~g}$ of Lys (template protein) and $0.02 \mathrm{~g}$ of MBAA (cross-linker) were added. $\mathrm{Fe}_{3} \mathrm{O}_{4} @$ VTEO $(0.1 \mathrm{~g})$ was suspended in $10 \mathrm{~mL}$ of phosphate buffer solution and mixed thoroughly by sonication. The resulting suspension was poured into former solution and shaken at rate of $200 \mathrm{rpm}$ for $1.5 \mathrm{~h}$ for pre-polymerization. Then the mixture was purged with nitrogen for $10 \mathrm{~min}$. After adding $75 \mu \mathrm{L}$ of APS $(20 \% \mathrm{w} / \mathrm{v})$ and $75 \mu \mathrm{L}$ of TEMED $(20 \% \mathrm{v} / \mathrm{v})$ to the mixture, polymerization reaction was initiated. The reaction continued under shaking condition at room temperature for $24 \mathrm{~h}$. The highly cross-linked polymer network was subsequently formed. After that, the samples were washed successively with $2 \%(\mathrm{w} / \mathrm{v})$ SDS-2\% (v/v) HAc solution to remove the template protein. It was then further washed with deionized water, collected by a magnet and dried by freeze-drying for further use.

Similarly, the magnetic ionic liquid non-imprinted polymers $\left(\mathrm{Fe}_{3} \mathrm{O}_{4} @\right.$ @TEO@IL-NIPs) were synthesised in the same procedure but without adding template protein.

\subsection{Protein adsorption experiments}

Batch rebinding studies have been carried out to investigate the template binding. The solvent of protein adsorption experiments is same as the solvent used during synthesis. $\mathrm{Fe}_{3} \mathrm{O}_{4} @$ @VTEO@IL-MIPs or $\mathrm{Fe}_{3} \mathrm{O}_{4} @$ QVTEO@IL-NIPs (5 mg) were mixed in Lys solution $(1 \mathrm{~mL})$ with different initial concentrations $(0.8-$ $2.0 \mathrm{mg} \mathrm{mL}^{-1}$ ) in phosphate buffer solution. The mixture was then shaken at $25^{\circ} \mathrm{C}$ for a period of time. The adsorbent was collected with the help of an external magnet, and the concentration of Lys in the supernatant was measured by UV-vis

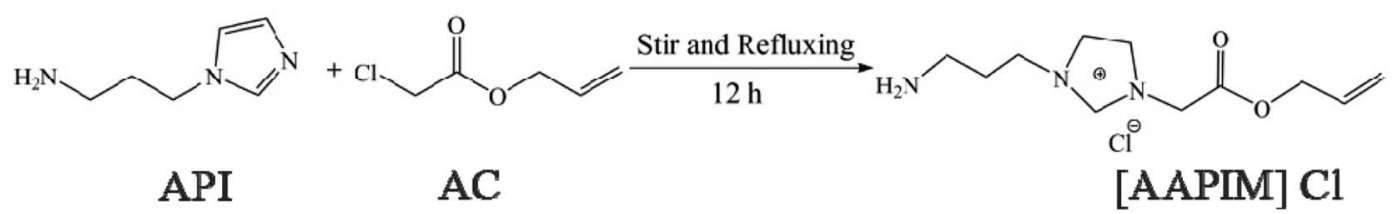

Fig. 1 Synthesis of ionic liquid [AAPIM]Cl. 
at wavelength of $280 \mathrm{~nm}$. The adsorption capacity of $\mathrm{Fe}_{3} \mathrm{O}_{4}$ @VTEO@IL-MIPs or $\mathrm{Fe}_{3} \mathrm{O}_{4} @ V T E O @ I L-N I P s$ for Lys was calculated according to the following formula:

$$
Q=\frac{\left(C_{0}-C_{\mathrm{F}}\right) V}{M}
$$

where $Q$ is the adsorption capacity $\left(Q, \mathrm{mg} \mathrm{g}^{-1}\right)$, which stands for the mass of protein adsorbed by unit mass of dry particles. $C_{0}$ $\left(\mathrm{mg} \mathrm{mL}^{-1}\right)$ and $C_{\mathrm{F}}\left(\mathrm{mg} \mathrm{mL}^{-1}\right)$ are the initial and final concentration of Lys solution. $V(\mathrm{~mL})$ presents the total volume of the Lys solution, and $M(\mathrm{~g})$ denotes the weight of polymer microspheres in each adsorption solution.

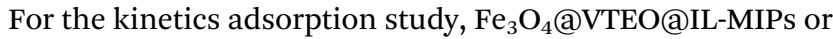
$\mathrm{Fe}_{3} \mathrm{O}_{4}$ @VTEO@IL-NIPs (5 mg) were dispersed in $1 \mathrm{~mL}$ of Lys solution with same initial concentration and incubated at designated time intervals.

\subsection{Selectivity experiments}

The selectivity of imprinted polymers was tested for binding of Lys, OVA, Cyt C, BSA and BHb. All the initial concentration of protein solution is same. After reaching adsorption equilibrium, the concentrations of five proteins in the supernatant were determined by UV-vis respectively at wavelength of $280 \mathrm{~nm}, 278 \mathrm{~nm}, 406 \mathrm{~nm}, 278 \mathrm{~nm}, 404 \mathrm{~nm}$, respectively. The imprinting factor (IF) was used to evaluate the selective extraction property of MIPs, which is defined as:

$$
\mathrm{IF}=\frac{Q_{\mathrm{MIP}}}{Q_{\mathrm{NIP}}}
$$

where $Q_{\text {MIP }}$ and $Q_{\text {NIP }}$ are the adsorption capacities of protein adsorbed by MIPs and NIPs, respectively. In addition, the separation factor $(R)$ is defined as:

$$
R=\frac{\mathrm{IF}_{\mathrm{tem}}}{\mathrm{IF}_{\mathrm{ana}}}
$$

Where $\mathrm{IF}_{\text {tem }}$ is the imprinting factor for the template molecules and $\mathrm{IF}_{\mathrm{ana}}$ is the imprinting factor for the analogues.

\subsection{Real sample adsorption experiments}

In the real sample tests, the chicken egg white sample was collected from fresh eggs and diluted 10-fold with phosphate buffer (20 mM, pH 7.1). $\mathrm{Fe}_{3} \mathrm{O}_{4} @$ @TEO@IL-MIPs or $\mathrm{Fe}_{3} \mathrm{O}_{4} @$ VTEO@IL-NIPs was added and shaken at room temperature for $12 \mathrm{~h}$. The microspheres were treated with $2 \%(\mathrm{w} / \mathrm{v})$ SDS- $2 \%(\mathrm{v} / \mathrm{v})$ HAc solution to elute the strongly adsorbed Lys. Finally, the diluted, adsorbed samples were analyzed by sodium dodecyl sulfate polyacrylamide gel electrophoresis (SDS-PAGE) with $12 \%$ polyacrylamide separating gel.

\section{Results and discussion}

\subsection{Preparation of $\mathrm{Fe}_{3} \mathrm{O}_{4} @ V T E O @ I L-M I P s$ for Lys}

To obtain a kind of material with surface hydrophilic and multiple binding sites for adsorption of Lys, magnetic ionic liquid imprinted polymers were designed through 3 different steps. In the first step, $\mathrm{Fe}_{3} \mathrm{O}_{4}$ nanoparticles were synthesized according to the chemical coprecipitation method, and then functionalized with polymerizable vinyl groups by reacting with VTEO. The silica coated on the surface of magnetic $\mathrm{Fe}_{3} \mathrm{O}_{4}$ nanoparticles prevents them from oxidation and agglomeration and make them more easily coated by polymers. ${ }^{27}$ Subsequently, the imprinted layer forming on the surface of $\mathrm{Fe}_{3} \mathrm{O}_{4}$ @VTEO can rebind template selectively through multiple interactions between Lys and IL, such as electrostatic interaction, hydrogen bonding and $\pi-\pi$ stacking. MBAA, as a hydrophilic crosslinking agent, was employed to form the template-monomer interaction network. Better aqueous dispersibility can be brought by introduction of water soluble additives. ${ }^{28}$ Polymerization was initiated by adding APS and TEMED for $24 \mathrm{~h}$. Lys was eluted from the MIPs layer using a mixture of SDS and HAc ( $2 \%$ $\mathrm{w} / \mathrm{v}: 2 \% \mathrm{v} / \mathrm{v}$ ). The solid product and liquid phases were separated by an external magnetic field quickly. After Lys was eluted successfully, the product was washed with distilled water, and dried by freeze-drying for $12 \mathrm{~h}$ successively for further use.

The selective extraction capability of Lys-imprinted polymers is mainly dependent on monomers. The amount of IL during imprinting was investigated in the range of $100-300 \mathrm{mg}$ (as shown in ESI Table S1 $\dagger$ ). The corresponding rebinding capacities and IF were shown in Fig. 2. When the mass of [AAPIM]Cl (IL) increased to $200 \mathrm{mg}, \mathrm{Fe}_{3} \mathrm{O}_{4}$ @VTEO@IL-MIPs exhibits increased adsorption for Lys, and the best value of $Q$ was obtained. The maximum adsorption capability of the $\mathrm{Fe}_{3} \mathrm{O}_{4}$ @VTEO@IL-MIPs is $170.1 \mathrm{mg} \mathrm{g}^{-1}$ and the IF is 2.16 . The reason why $Q$ increased is that higher amount of IL could facilitate the interaction between monomer and Lys, thus leading to more imprinted sites on the surface of $\mathrm{Fe}_{3} \mathrm{O}_{4} @$ VTEO@IL-MIPs. However, it is noteworthy that MIP4 and MIP5 suffered from decreased adsorption capacity with increasing amount of IL. This is because the thicker imprinted polymer layer blocked the imprinted cavities. Moreover, the optimized monomer amount (200 mg) was selected for the following investigation.

\subsection{Characterization of $\mathrm{Fe}_{3} \mathrm{O}_{4} @ V T E O @ I L-M I P s$}

All details and figures about FT-IR spectra, TEM, DLS, VSM, TGA, and XRD analyses are mentioned in ESI Fig. S1-S6. $\dagger$

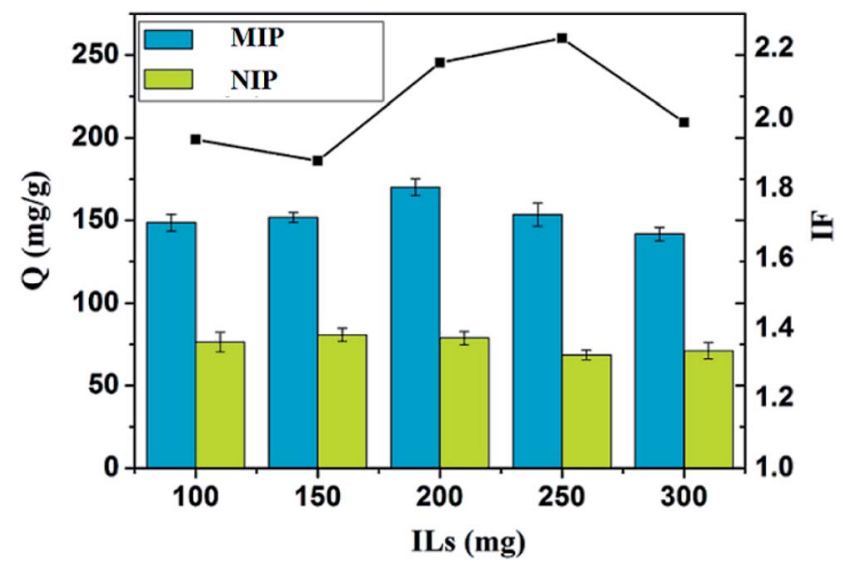

Fig. 2 The influence of monomer amount on adsorption capacities of $\mathrm{Fe}_{3} \mathrm{O}_{4}$ @VTEO@IL-MIPs and $\mathrm{Fe}_{3} \mathrm{O}_{4}$ @VVTEO@IL-NIPs. Adsorption conditions: $V=1 \mathrm{~mL}, m_{\mathrm{MIPs}}=m_{\mathrm{NIPs}}=5 \mathrm{mg}, C_{\mathrm{Lys}}=1.0 \mathrm{mg} \mathrm{mL}^{-1}, T=$ $25^{\circ} \mathrm{C}, t=24 \mathrm{~h}, \mathrm{pH}=7.1$. 


\subsection{Adsorption isotherms}

Lys concentration has a significant effect on the adsorption capacities of the imprinted and non-imprinted magnetic ionic liquid polymers. The results were shown in Fig. 3. The adsorption capacity of $\mathrm{Fe}_{3} \mathrm{O}_{4} @$ VTEO@IL-MIPs (NIPs) increased obviously when the concentration of Lys vary from 0.8 to $1.2 \mathrm{mg}$ $\mathrm{mL}^{-1}$. The adsorption capacity of $\mathrm{Fe}_{3} \mathrm{O}_{4} @ V T E O @ I L-M I P s$ increased continuously but the adsorption capacity of $\mathrm{Fe}_{3}$ $\mathrm{O}_{4} @ V T E O @ I L-N I P s$ decreased when the concentration of Lys increased to $1.4 \mathrm{mg} \mathrm{mL}{ }^{-1}$. When the concentration of Lys is $1.4 \mathrm{mg} \mathrm{mL}{ }^{-1}$, the maximum adsorption capacity of $\mathrm{Fe}_{3} \mathrm{O}_{4}$ @VTEO@IL-MIPs (217.39 $\mathrm{mg} \mathrm{g}^{-1}$ ) was obtained, which is higher than that of $\mathrm{Fe}_{3} \mathrm{O}_{4} @$ VTEO@IL-NIPs (120.42 $\mathrm{mg} \mathrm{g}^{-1}$ ). As the concentration of Lys increased further, the adsorption capacity of $\mathrm{Fe}_{3} \mathrm{O}_{4} @ V T E O @ I L-M I P s$ reduced and the adsorption capacity of $\mathrm{Fe}_{3} \mathrm{O}_{4} @ V T E O @ I L-N I P s$ did not change too much. So it suggests that $1.4 \mathrm{mg} \mathrm{mL}^{-1}$ is the suitable concentration of Lys. The result indicates there are affinity binding sites generated on the surface of $\mathrm{Fe}_{3} \mathrm{O}_{4}$ @IL-MIPs.

The experimental data were then fitted for the Langmuir model. The details and figure and table were shown in ESI Fig. S7 and Table S2. $†$

\subsection{Adsorption kinetics}

Adsorption time was investigated in the range of $0.5-5 \mathrm{~h}$. The rebinding kinetics was studied with an initial Lys concentration of $1.4 \mathrm{mg} \mathrm{mL}^{-1}$. The relationship between the adsorption capacity of $\mathrm{Fe}_{3} \mathrm{O}_{4} @$ @TEO@IL-MIPs (NIPs) and adsorption time was indicated in Fig. 4. Adsorption capacity of $\mathrm{Fe}_{3} \mathrm{O}_{4} @$ VTEO@IL-MIPs increased rapidly in the first hour and continued to increase until $\mathrm{Fe}_{3} \mathrm{O}_{4} @$ VTEO@IL-MIPs attained adsorption equilibrium after $2.5 \mathrm{~h}$. When the adsorption time is $2.5 \mathrm{~h}$, the adsorption capacity of $\mathrm{Fe}_{3} \mathrm{O}_{4}$ @VTEO@IL-MIPs is $213.7 \mathrm{mg} \mathrm{g}^{-1}$, but the adsorption capacity of

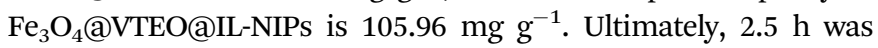
selected as the optimum adsorption time. The high adsorption rate of the $\mathrm{Fe}_{3} \mathrm{O}_{4} @$ @TEO@IL-MIPs proves once again that the surface of the $\mathrm{Fe}_{3} \mathrm{O}_{4} @$ VTEO@IL-MIPs produces imprinted cavities

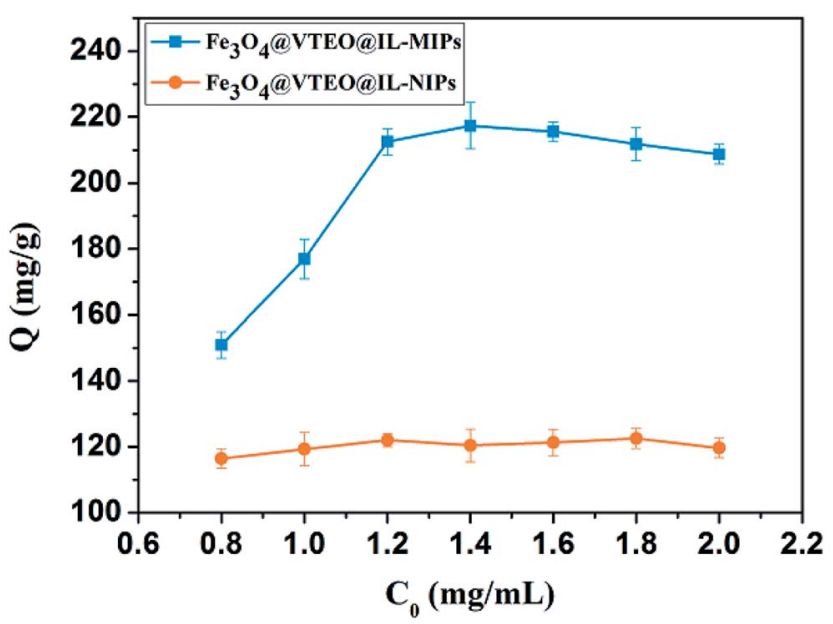

Fig. 3 The adsorption isotherm of Lys on $\mathrm{Fe}_{3} \mathrm{O}_{4}$ @VTEO@IL-MIPs and $\mathrm{Fe}_{3} \mathrm{O}_{4}$ @VTEO@IL-NIPs. Adsorption conditions: $V=1 \mathrm{~mL}, m_{\text {MIPs }}=$ $m_{\mathrm{NIPs}}=5 \mathrm{mg}, C_{\text {Lys }}=0.8-2.0 \mathrm{mg} \mathrm{mL}^{-1}, T=25^{\circ} \mathrm{C}, t=12 \mathrm{~h}$.

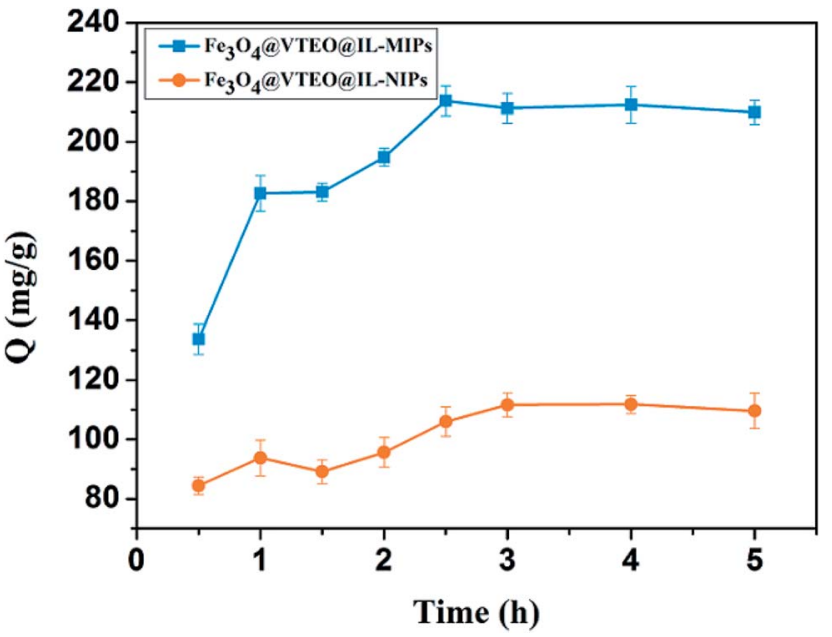

Fig. 4 The adsorption kinetics of Lys on $\mathrm{Fe}_{3} \mathrm{O}_{4}$ @VTEO@IL-MIPs and $\mathrm{Fe}_{3} \mathrm{O}_{4}$ @VTEO@IL-NIPs. Adsorption conditions: $V=1 \mathrm{~mL}, m_{\text {MIPs }}=$ $m_{\mathrm{NIPs}}=5 \mathrm{mg}, C_{\text {Lys }}=1.4 \mathrm{mg} \mathrm{mL}^{-1}, T=25^{\circ} \mathrm{C}$.

during the imprinting process. The imprinted sites locating at the surface of polymers or near the surface make template molecules easily access to the cavities.

\subsection{Selective adsorption experiments}

In order to examine selective extraction ability of the imprinted particles for Lys, we selected four kinds of reference proteins for the selective adsorption experiments. The isoelectric points (pI) and molecular weight $\left(M_{\mathrm{w}}\right)$ of these proteins are different. The reference proteins include $\mathrm{BHb}(64.5 \mathrm{kDa}, \mathrm{pI} 6.8)$, BSA $(66.4 \mathrm{kDa}$, pI 4.7), Cyt C (12.4 kDa, 10.0), and OVA (43 kDa, pI 4.7). The $M_{\mathrm{w}}$ and $\mathrm{pI}$ of Lys are $14.4 \mathrm{kDa}$ and 10.8 , respectively. The template protein has matched size, shape and the placement of functional groups with MIPs. As a result, the adsorption capacity of $\mathrm{Fe}_{3}$ $\mathrm{O}_{4}$ @VTEO@IL-MIPs to Lys is larger than others reference proteins obviously, which was shown in Fig. 5. BHb and BSA have similar molecular size which is larger than Lys too much. Owing to the strong steric hindrance, it is difficult for BHb and BSA to

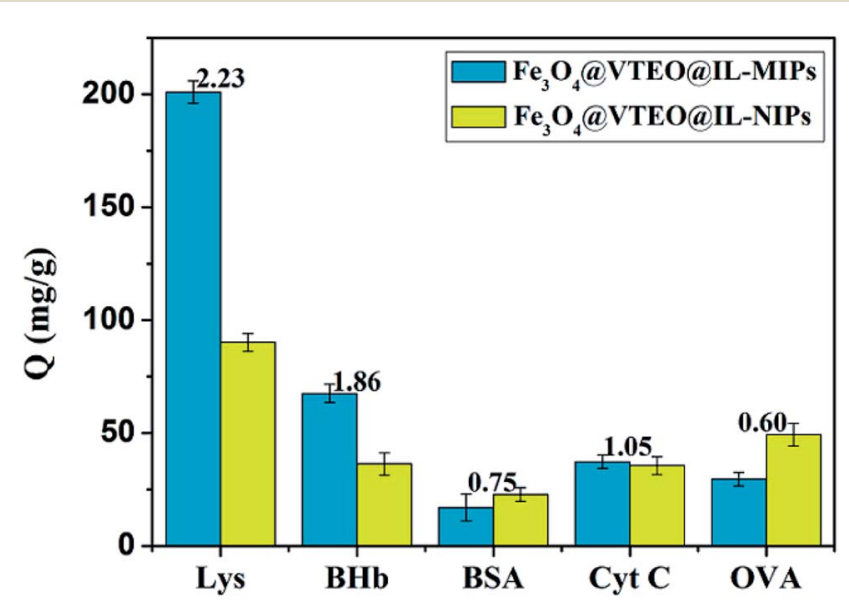

Fig. 5 Adsorption capacities of different proteins on $\mathrm{Fe}_{3} \mathrm{O}_{4} \mathrm{a}$ VTEO@IL-MIPs and $\mathrm{Fe}_{3} \mathrm{O}_{4}$ QVTEO@IL-NIPs. Adsorption conditions: $V$ $=1 \mathrm{~mL}, m_{\text {MIPs }}=m_{\mathrm{NIPs}}=5 \mathrm{mg}, C_{0}=1.4 \mathrm{mg} \mathrm{mL}^{-1}, T=25^{\circ} \mathrm{C}, t=2.5 \mathrm{~h}$. 
access to the imprinted cavities. Or, from another perspective, $\mathrm{BHb}$ was negatively charged while Lys was positively charged at $\mathrm{pH}$ 7.1, so that electrostatic repulsion between the BHb and MIPs is strong, which is similar to BSA and OVA. Although the size and pI of Cyt C is similar to Lys, the adsorption capacity of MIPs to Cyt $\mathrm{C}$ is only $37.2 \mathrm{mg} \mathrm{g}^{-1}$, which is due to the mismatched placement of functional groups. All the results investigate that the imprinted particles have selective extraction ability of Lys. The calculated imprinting factor and selectivity factor were given in Table 1. It can be seen that the magnetic imprinted particles show the highest selectivity to the template Lys than others four reference proteins, which confirms $\mathrm{Fe}_{3} \mathrm{O}_{4} @$ VTEO@IL-MIPs can extract template proteins selectively.

\subsection{Competitive batch rebinding tests and real sample adsorption experiments}

To better compare the selective extraction ability of $\mathrm{Fe}_{3} \mathrm{O}_{4}$ @VTEO@IL-MIPs to Lys, competitive adsorption experiments were carried out in binary protein mixture of Lys and $\mathrm{BHb}$. Lys and $\mathrm{BHb}$ have same initial concentration. BHb was chosen as a competitive protein, which is because the highest adsorption capacity than others proteins in selective adsorption experiments. The results of SDS-PAGE analysis for the Lys and BHb binary solution were shown in ESI Fig. S8. $\uparrow$ The corresponding band of Lys appeared at around $10-15 \mathrm{kDa}$. Though the molecular weight of $\mathrm{BHb}$ is 64.5 $\mathrm{kDa}$, the band of $\mathrm{BHb}$ appeared at $10-15 \mathrm{kDa}$ also owing to depolymerization in SDS. Both the $\mathrm{BHb}$ and Lys bands of the binary solution after adsorption by $\mathrm{Fe}_{3} \mathrm{O}_{4} @ V T E O @ I L-M I P s$ (lane 3) became shallow compared with the initial binary protein mixture (lane 4). It is clear that there is a band at $c a .32 \mathrm{KD}$, which maybe because $\mathrm{BHb}$ depolymerized in SDS incompletely. Though $\mathrm{BHb}$ was absorbed to some extent in the competitive batch rebinding tests, the color of Lys band became shallow obviously. It is an effective strategy to imprint and separate Lys.

Chicken egg white was taken as the real sample so as to demonstrate the practical applicability of $\mathrm{Fe}_{3} \mathrm{O}_{4} @ V T E O @ I L-$ MIPs. As indicated in ESI Fig. S9, $\uparrow$ chicken egg white after adsorption by the $\mathrm{Fe}_{3} \mathrm{O}_{4}$ @VTEO@IL-MIPs exhibited a lighter blue (lane 3) band of Lys, but the band of Lys was no significant change after adsorption by the $\mathrm{Fe}_{3} \mathrm{O}_{4} @$ VTEO@IL-NIPs (lane 4).

Table 1 The selectivity adsorption of $\mathrm{Fe}_{3} \mathrm{O}_{4}$ @VTEO@IL-MIPs to Lys, $\mathrm{BHb}, \mathrm{BSA}$, Cyt $\mathrm{C}$ and OVA

\begin{tabular}{llll}
\hline Parameter & IF $^{a}$ & $R^{b}$ & $\left(Q_{\text {MIP }}\right)$ tem $/\left(Q_{\text {MIP }}\right)$ ana $^{c}$ \\
\hline Lys & 2.23 & - & - \\
BHb & 1.86 & 1.20 & 2.97 \\
BSA & 0.75 & 2.97 & 11.87 \\
Cyt C & 1.05 & 2.12 & 5.39 \\
OVA & 0.60 & 3.72 & 6.81
\end{tabular}

${ }^{a} \mathrm{IF}=\frac{Q_{\mathrm{MIP}}}{Q_{\mathrm{NIP}}}$, where IF is the imprinting factor for the template molecules. ${ }^{b} R=\frac{\mathrm{IF}_{\text {tem }}}{\mathrm{IF}_{\mathrm{ana}}}$, where $R$ is the separation factor. ${ }^{c}\left(Q_{\mathrm{MIP}}\right)$ tem is the adsorption capacity of the MIP for the extraction of template, and $\left(Q_{\text {MIP }}\right)$ ana is the adsorption capacity of the MIP for the extraction of the analogs.

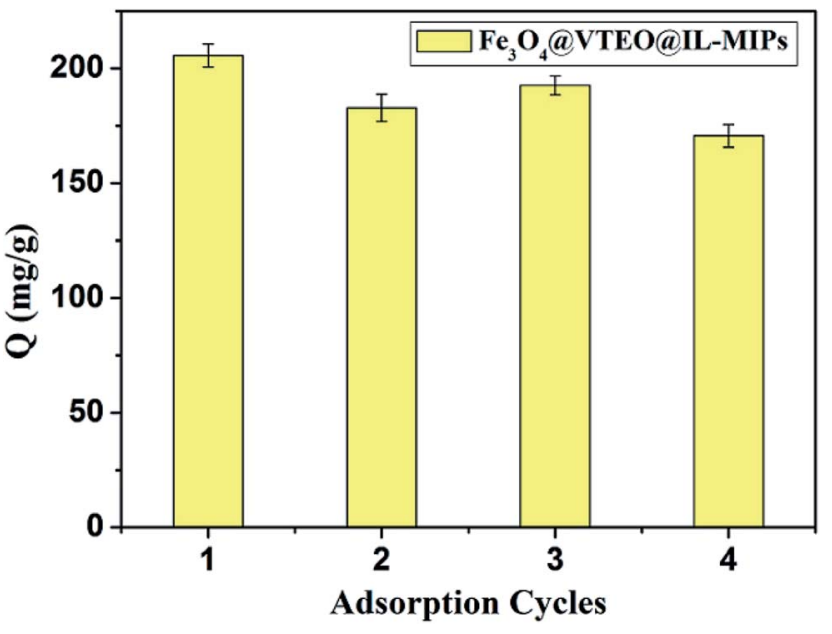

Fig. 6 Reusability of $\mathrm{Fe}_{3} \mathrm{O}_{4}$ @VTEO@IL-MIPs.

The obtained results indicate that the $\mathrm{Fe}_{3} \mathrm{O}_{4}$ @VTEO@IL-MIPs have potential to separate Lys from chicken egg white.

\subsection{Reusability and stability of magnetic ionic liquid imprinted polymers}

The reusability of adsorbents is important, which is considered to have a great cost benefit. ${ }^{29}$ The results were shown in Fig. 6 . The

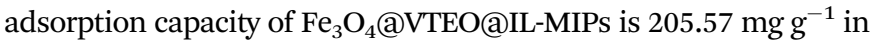
the first time, and it reduced to $170.65 \mathrm{mg} \mathrm{g}^{-1}$ after four adsorption cycles. The results exhibits that the reusability of the measurement is charming which is still above $83 \%$ in the final recycling. Some imprinted cavities were destroyed were not eluted entirely when rewashing, which led to slight loss of adsorption capacity. The phenomenon indicates that the magnetic ionic liquid imprinted polymers have good reusability and stability. Furthermore, The CD spectra and the UV-visible spectra of Lys were mentioned in Fig. S10 and S11 $\uparrow$ to prove the structures of Lys doesn't be changed.

\subsection{Comparison with other reported methods}

$\mathrm{Fe}_{3} \mathrm{O}_{4} @ V T E O @ I L-M I P s$ in this work was compared with some other reported Lys imprinted polymers. ${ }^{30-33}$ It can be seen from Table 2 that the adsorption capacity of $\mathrm{Fe}_{3} \mathrm{O}_{4}$ @VTEO@IL-MIPs is

Table 2 An overview on other methods for adsorption and selective extraction of Lys

\begin{tabular}{llll}
\hline Imprinting method & $Q^{a}\left(\mathrm{mg} \mathrm{g}^{-1}\right)$ & IF & References \\
\hline Entrapment & - & 8.6 & 12 \\
imprinting & & & \\
Surface imprinting & $\sim 150$ & $\sim 1.1$ & 30 \\
Surface imprinting & 108 & 2.82 & 31 \\
Surface imprinting & 101 & $\sim 4$ & 32 \\
Surface imprinting & 700 & $>4$ & 33 \\
Surface imprinting & 213.7 & 2.02 & This method
\end{tabular}

${ }^{a} Q=\frac{\left(C_{0}-C_{\mathrm{F}}\right) V}{M}$, where $Q$ is the adsorption capacity of the MIP for the extraction of template molecules. 
higher than some imprinted polymers for Lys. The adsorption capacity of the MIPs for Lys in this paper can attain $213.7 \mathrm{mg} \mathrm{g}^{-1}$ and the imprinting factor is 2.02 . The SD and RSD obtained is 0.9609 and $0.433 \%$, respectively $(n=6)$, demonstrating the precision of the UV-vis spectrometer is excellent. Although the adsorption capacity and IF is not the best, a new functional monomer was put forward.

\section{Conclusions}

In summary, a new core-shell IL molecularly imprinted polymers was synthesized for highly selective extraction of Lys based on double bond-functionalized $\mathrm{Fe}_{3} \mathrm{O}_{4}$ nanoparticles. $\mathrm{Fe}_{3} \mathrm{O}_{4}$ nanoparticles were protected by polymers, which can prevent $\mathrm{Fe}_{3} \mathrm{O}_{4}$ nanoparticles oxidized and conglomerated. [AAPIM] Cl, the functional monomer of the MIPs, can form strong interactions with template and remarkably improved the imprinting effect. TEM, DLS, TGA, XRD, VSM and FT-IR were used to characterize the composition and morphology of the prepared MIPs. The adsorption capacity of the MIPs for Lys can attain $213.7 \mathrm{mg} \mathrm{g}^{-1}$ and the IF is 2.02. In addition, $2.5 \mathrm{~h}$ was chosen as the suitable adsorption time. The high adsorption performance of the MIPs is attractive. From the reusability experiments, it can be seen that the magnetic MIPs microspheres can be used four times at least. Furthermore, $\mathrm{Fe}_{3} \mathrm{O}_{4} @ V T E O @ I L-M I P s$ can separate Lys from chicken egg white real sample successfully. In a word, this paper provides an effective strategy to imprint and separate Lys. And our future work is to synthesis better MIPs for selective extraction to Lys.

\section{Conflicts of interest}

There are no conflicts to declare.

\section{Acknowledgements}

The authors greatly appreciate the financial supports by the National Natural Science Foundation of China (No. 21675048) and the Foundation for Innovative Research Groups of NSFC (Grant 21521063).

\section{References}

1 H. Ding, R. Chen, M. Liu, R. Huang, Y. Du, C. Huang, X. Yu, X. Feng and F. Liu, RSC Adv., 2016, 6, 43526-43538.

2 L. Chen, X. Wang, W. Lu, X. Wu and J. Li, Chem. Soc. Rev., 2016, 45, 2137-2211.

3 X. M. Zhang, Y. P. Qin, H. L. Ye, X. T. Ma, X. W. He, W. Y. Li and Y. K. Zhang, Microchim. Acta, 2018, 185, 173.

4 X. Chen and N. Ye, RSC Adv., 2017, 7, 34077-34085.

5 B. Singh and N. Chauhan, Acta Biomater., 2008, 4, 1244-1254.

6 H. Duan, L. Li, X. Wang, Y. Wang, J. Li and C. Luo, RSC Adv., 2015, 5, 18850-18857.

7 J. Guo, Y. Wang, Y. Liu and Y. Zhou, Anal. Methods, 2015, 7, 10018-10025.
8 Y. Liu, Y. Wang, Q. Dai and Y. Zhou, Anal. Chim. Acta, 2016, 936, 168-178.

9 S. Xu, H. Lu, L. Chen and X. Wang, RSC Adv., 2014, 4, 4526645274.

10 X. Wang, P. Huang, X. Ma, X. Du and X. Lu, J. Chromatogr. A, 2018, 1537, 35-42.

11 S. J. Cho, H. B. Noh, M. S. Won, C. H. Cho, K. B. Kim and Y. B. Shim, Biosens. Bioelectron., 2018, 99, 471-478.

12 T. Kubo, S. Arimura, Y. Tominaga, T. Naito, K. Hosoya and K. Otsuka, Macromolecules, 2015, 48, 4081-4087.

13 E. Shoghi, S. Z. Mirahmadi-Zare, R. Ghasemi, M. Asghari, M. Poorebrahim and M. H. Nasr-Esfahani, Microchim. Acta, 2018, 185, 241.

14 S. H. Ou, M. C. Wu, T. C. Chou and C. C. Liu, Anal. Chim. Acta, 2004, 504, 163-166.

15 C. Ocaña, A. Hayat, R. Mishra, A. Vasilescu, M. D. Valle and J. L. Marty, Analyst, 2015, 140, 4148-4153.

16 Q. Yang, Y. Wang, H. Zhang, K. Xu, X. Wei, J. Chen and P. Xu, RSC Adv., 2017, 7, 53203-53209.

17 Q. Wen, Y. Wang, K. Xu, N. Li, H. Zhang and Q. Yang, Anal. Chim. Acta, 2016, 939, 54-63.

18 X. Wei, Y. Wang, J. Chen, P. Xu and Y. Zhou, Talanta, 2018, 182, 484-491.

19 Q. Zhao, J. C. Wajert and J. L. Anderson, Anal. Chem., 2010, 82, 707-713.

20 H. Xiang, M. Peng, H. Li, S. Peng and S. Shi, J. Pharm. Biomed. Anal., 2017, 133, 75-81.

21 L. Zhao, J. Yang, H. Ye, F. Zhao and B. Zeng, RSC Adv., 2017, 7, 4704-4709.

22 M. Liu, J. Pi, X. Wang, R. Huang, Y. Du, X. Yu, W. Tan, F. Liu and K. J. Shea, Anal. Chim. Acta, 2016, 932, 29-40.

23 J. Chen, Y. Wang, Q. Zeng, X. Ding and Y. Huang, Anal. Methods, 2014, 6, 4067-4076.

24 Q. Dai, Y. Wang, W. Xu, Y. Liu and Y. Zhou, Microchim. Acta, 2017, 184, 4433-4441.

25 J. Xie, G. Zhong, C. Cai, C. Chen and X. Chen, Talanta, 2017, 169, 98-103.

26 Q. Gai, F. Qu, Z. J. Liu, R. J. Dai and Y. K. Zhang, J. Chromatogr. A, 2010, 1217, 5035-5042.

27 N. Li, L. Qi, Y. Shen, J. Qiao and Y. Chen, ACS Appl. Mater. Interfaces, 2014, 6, 17289-17295.

28 J. Xu, Y. Wang and S. Hu, Microchim. Acta, 2017, 184, 1-44.

29 R. Gao, Y. Hao, L. Zhang, X. Cui, D. Liu, M. Zhang, Y. Tang and Y. Zheng, Chem. Eng. J., 2016, 284, 139-148.

30 S. Ji, N. Li, Y. Shen, Q. Li, J. Qiao and Z. Li, Anal. Chim. Acta, 2016, 909, 60-66.

31 K. Xu, Y. Wang, X. Wei, J. Chen, P. Xu and Y. Zhou, Microchim. Acta, 2018, 185, 146.

32 H. Duan, X. Wang, Y. Wang, Y. Sun, J. Li and C. Luo, Anal. Chim. Acta, 2016, 918, 89-96.

33 J. Chen, S. Lei, Y. Xie, M. Wang, J. Yang and X. Ge, ACS Appl. Mater. Interfaces, 2015, 7, 28606-28615. 